\title{
ETNOGRAFIA: SABERES E PRÁTICAS ${ }^{1}$
}

\author{
Ana Luiza Carvalho da Rocha
}

Cornelia Eckert

\begin{abstract}
Passando de uma atividade exclusivamente literária a prática da etnografia, eu pensava romper com os hábitos intelectuais que tinham sido os meus até agora, através do contato com homens de outra cultura e raça que não as minhas, e com as muralhas que me sufocavam, expandindo meu horizonte para uma medida verdadeiramente humana. (Michel Leiris, 1934)
\end{abstract}

\section{Método etnográfico? Técnicas de pesquisa etnográfica?}

É frequiente se afirmar que o método etnográfico é aquele que diferencia as formas de construção de conhecimento em Antropologia em relação a outros campos de conhecimento das ciências humanas. De fato o método etnográfico encontra sua especificidade em ser desenvolvido no âmbito da disciplina antropológica, sendo composto de técnicas e de procedimentos de coletas de dados associados a uma prática do trabalho de campo a partir de uma convivência mais ou menos prolongada do(a) pesquisador(a) junto ao grupo social a ser estudado. A prática da pesquisa de campo etnográfica responde, pois a uma demanda científica de produção de dados de conhecimento antropológico a partir de uma inter-relação entre o(a) pesquisador(a) e o(s) sujeito(s) pesquisados que interagem no contexto recorrendo primordialmente as técnicas de pesquisa da observação direta, de conversas informais e formais, as entrevistas não-diretivas, etc.

Desde já esclarecemos ao (à) aluno(a) de graduação que o método etnográfico é um método específico da pesquisa antropológica. Outras ciências sociais recorrem não obstante a determinadas técnicas de pesquisas que são singulares ao método de pesquisa qualitativa. Mas neste caso trata-se de adotar alguns procedimentos técnicos próprios da pesquisa etnográfica como a observação e as entrevistas, vinculadas agora a outros campos teóricos

\footnotetext{
1 Artigo publicado no livro organizado por Céli Regina Jardim Pinto e César Augusto Barcellos Guazzelli Ciências Humanas: pesquisa e método. Porto Alegre: Editora da Universidade, 2008.
} 
de interpretação da realidade social que não a teoria antropológica.

Já o método etnográfico é a base na qual se apóia o edifício da formação de um(a) antropólogo(a). A pesquisa etnográfica constituindo-se no exercício do olhar (ver) e do escutar (ouvir) impõe ao pesquisador ou a pesquisadora um deslocamento de sua própria cultura para se situar no interior do fenômeno por ele ou por ela observado através da sua participação efetiva nas formas de sociabilidade por meio das quais a realidade investigada se lhe apresenta.

Inicialmente, em Antropologia, a preparação para o trabalho de campo implica inúmeras etapas, uma delas é a construção do próprio tema e objeto de pesquisa desde a adoção de determinados recortes teórico-conceituais do próprio campo disciplinar e suas áreas de conhecimento (Antropologia rural, Antropologia urbana, etc.). Não é usual este projeto contemplar hipóteses iniciais de pesquisa uma vez que estas emergem na medida em que a investigação avança com a aproximação ao universo a ser pesquisado.

\section{A observação direta}

Se o método etnográfico é composto por inúmeros procedimentos incluindo levantamento de dados de pesquisa probabilística e quantitativa (demografia, morfologia, geografia, genealogia, etc.), a observação direta é sem dúvida a técnica privilegiada para investigar os saberes e as práticas na vida social e reconhecer as ações e as representações coletivas na vida humana. É se engajar em uma experiência de percepção de contrastes sociais, culturais, e históricos. As primeiras inserções no universo de pesquisa conhecidas como "saídas exploratórias", são norteadas pelo olhar atento ao contexto e a tudo que acontece no espaço observado. A curiosidade é logo substituída por indagações sobre como a realidade social é construída. Esta demanda é habitada por aspectos comparativos que nascem da inserção densa do pesquisador no compromisso de refletir sobre a vida social, estando antes de mais nada disposto a vivenciar a experiência de inter-subjetividade, sabendo que ele próprio passa a ser objeto de observação (Lévi-Strauss, 1974, p. 1 à 36). O (A) aprendiz a antropólogo(a) coteja os aspectos que percebe cada vez mais orientados por questões teórico-conceituais apreendidas já nos primeiros anos do curso de ciências humanas. 
Após a elaboração de um projeto com tema pertinente ao campo de conhecimento antropológico e orientado por um(a) professor(a) que lhe iniciará na pesquisa etnográfica, a primeira atitude do(da) jovem cientista é aproximar-se das pessoas, dos grupos ou da instituição a ser estudada para conquistar a concordância de sua presença para a observação sistemática das práticas sociais.

A interação é a condição da pesquisa. Não se trata de um encontro fortuito, mas de

uma relação que se prolonga no fluxo do tempo e na pluralidade dos espaços sociais vividos cotidianamente por pessoas no contexto urbano, no mundo rural, nas terras indígenas, nos territórios quilombolas, enfim, nas casas, nas ruas, na roça, etc, que abrangem o mundo público e o mundo privado da sociedade em geral.

Logo após o pedido de consentimento por parte dos indivíduos ou das pessoas, ou da concordância institucional, o(a) pesquisador(a)-observador(a), em sua atitude de estar presente com regularidade, passa a participar das rotinas do grupo social estudado e sua técnica consiste então na observação participante. A prática da etnografia se torna mais profunda e se constitui como uma forma do(a) antropólogo(a) pesquisar, na vida social, os valores éticos e morais, os códigos de emoções, as intenções e as motivações que orientam a conformação de uma determinada sociedade.

É recorrente se afirmar que o(a) antropólogo(a) não pode se transformar em nativo(a), submergindo integralmente ao seu ethos e visão de mundo, tanto quanto não pode aderir irrestritamente aos valores de sua própria cultura para interpretar e descrever uma cultura diferente da sua própria (o que consiste no etnocentrismo), sob pena de não mais ter as condições epistemológicas necessárias à produção da etnografia. O(a) antropólogo(a) brasileiro Roberto Da Matta (1978 e 1981), denomina este sentimento de estar lá e do estar aqui como parte das tristezas do(a) antropólogo(a), um eterno desgarrado de sua própria cultura, mas na eterna busca do seu encontro com outras culturas. Por isto podemos caracterizar a antropologia como a ciência que trata da diversidade cultural.

\section{O trabalho de conhecer}

A pesquisa de campo etnográfico consiste em estudarmos o Outro, como uma Alteridade, mas justamente para conhecer o Outro. A observação é então esta aprendizagem 
de olhar o Outro para conhecê-lo, e ao fazermos isto, também buscamos nos conhecer melhor. Esta busca de conhecimento é sempre orientada por questões conceituais aprendidas no estudo das teorias sociais. Todo tempo estamos, portanto, desenvolvendo o que o sociólogo francês Pierre Bourdieu definiu como uma teoria em ato (apud Thiollent, 1980). A cada percepção que nos permite refletir conceitualmente operamos o que o filósofo francês Gaston Bachelard ensinou em sua obra de iniciação "A formação do espírito científico" sobre como vencer obstáculos epistemológicos imbuídos de uma cultura científica. Fascinado pelas generalizações de primeira vista, logo somos mobilizados pela motivação científica e superamos as armadilhas de explicar o que observamos pelo senso comum. Ao recorrermos às idéias científicas podemos então ordenar nossas descobertas em uma lógica inteligente que provoca o conhecimento intelectual sobre o observado, sobre a situação pesquisada, sobre as dinâmicas sociais investigadas. Bachelard nos ensina aqui que vivemos no campo científico uma ruptura epistemológica (Bachelard, 1996).

Esta descoberta sobre o Outro, é uma relação dialética que implica em uma sistemática reciprocidade cognitiva entre o(a) pesquisador(a) e os sujeitos pesquisados.

A acuidade de observar as formas dos fenômenos sociais implica na disposição do(a) pesquisador(a) a permitir-se experimentar uma sensibilidade emocional para penetrar nas espessas camadas dos motivos e intenções que conformam as interações humanas, ultrapassando a noção ingênua de que a realidade é mensurável ou visível, em uma atitude individual. O observar na pesquisa de campo implica na interação com o Outro evocando uma habilidade para participar das tramas da vida cotidiana, estando com o Outro no fluxo dos acontecimentos. Isto implica em estar atento(a) as regularidades e variações de práticas e atitudes, reconhecer as diversidades e singularidades dos fenômenos sociais para além das suas formas institucionais e definições oficializadas por discursos legitimados por estruturas de poder.

A pesquisa se inicia pela aprovação de um projeto que contenha as intenções teóricas e categorias antropológicas que fundamentam as etapas do desenvolvimento do trabalho de campo sob a orientação de um professor(a)/pesquisador(a) antropólogo(a). Existem múltiplas maneiras da inserção em campo ser iniciada, mas em sua maioria, uma etnografia se estréia com um processo de negociação do(a) antropólogo(a) com indivíduos e/ou grupos que pretende estudar, transformando-os em parceiros de seus projetos de investigação, 
compartilhando com eles e com elas suas idéias e intenções de pesquisa. O consentimento implica em saber quando e onde ir, com quem e o que se pode ou não falar, como agir diante de situações de conflito e risco, etc. Algumas vezes o(a) antropólogo(a) é "iniciado(a)" no seu trabalho de campo por um dos membros do grupo que investiga. Em geral denominamos este(a) personagem que nos apóia nos primeiros passos no contexto da pesquisa de "interlocutor principal", quando não pela carinhosa denominação de padrinho ou madrinha de iniciação. Outras vezes se coloca em campo a partir do consentimento de uma determinada instituição que avalia a pertinência da pesquisa para sua concordância ou ainda uma organização que desenvolve ações junto ao grupo com o qual pretende trabalhar.

O antropólogo americano William Foote Whyte (2005) fez sua entrada em campo nas ruas da cidade. Buscava se aproximar dos moradores do quarteirão italiano de um bairro de Boston, Cornerville. Esta aproximação é mediada por um trabalhador que lhe apresentará Doc, chefe de um grupo de jovens que lhe colocará em contato com seus companheiros, através dos quais irá conhecer uma rede densa de relações no bairro. Fica evidente que a expressão «entrada em campo » possui uma rica ambigüidade. Para o(a) etnógrafo(a) "entrar em campo" significa tanto a permissão formal do "nativo" para que ele disponha de seu sistema de crenças e de práticas como objeto/tema de produção de conhecimento em antropologia, quanto o momento propriamente dito em que o(a) antropólogo(a) adquire a confiança do(a) nativo(a) e de seu grupo, os quais passam a aceitar se deixar observar pelo(a) etnógrafo(a) que passa, por sua vez, a participar de suas vidas cotidianas.

\section{A escuta atenta}

A entrada em campo sempre transcorre desde uma rede de interações tecidas pelo(a) antropólogo(a) no seu contato com um grupo determinado, sendo o trabalho de campo um laborioso trabalho de entrada do(a) etnógrafo(a) desde uma situação periférica no interior da vida coletiva deste grupo até seu deslocamento progressivo no coração dos dramas sociais vividos por seus membros. Obviamente não todos, mas aqueles aos quais o(a) antropólogo(a) aderiu em seu trabalho de campo. A experiência situada é aquela que orienta a prática da pesquisa em antropologia que jamais pretende atingir um conhecimento do mundo social a partir da posição que ele (ela) ocupa no seu interior. Todo o conhecimento 
produzido e acumulado pelo pensamento antropológico está referido a experiência singular que o(a) etnógrafo(a) desenvolve com a sociedade que investiga.

A inserção no contexto social objetivado pelo(a) pesquisador(a) para o desenvolvimento do seu tema de pesquisa, o(a) aproxima cada vez mais dos indivíduos, dos grupos sociais que circunscrevem seu universo de pesquisa. Junto a estas pessoas o(a) pesquisador(a) tece uma comunicação densa orientada pelo seu projeto de intenções de pesquisa.

A presença se prolonga e o(a) antropólogo(a) participa da vida social que pesquisa, interagindo com as pessoas no espaço cotidiano, compartilhando a experiência do tempo que flui. Esta comunicação se densifica com a aprendizagem da língua do "nativo" para a compreensão de suas falas quando necessário, com o reconhecimento dos sotaques ou das gírias, com a aprendizagem dos significados dos gestos, das performances e das etiquetas próprias ao grupo que revelam suas orientações simbólicas e traduzem seus sistemas de valores para pensar o mundo. O antropólogo americano Clifford Geertz (1978) sugere aqui que estaremos desvendando o tom e a qualidade da vida cultural, o ethos e o habitus do grupo, ou seja, estaremos interpretando o sistema simbólico que orienta a vida e conforma os valores éticos dos grupos sociais em suas ações e representações acerca de como viver em um sistema social. Isto significa estar junto nas situações ordinárias vividas como possibilidade interpretativa dos ditos e não ditos que se constituem como parte fundamental das aprendizagens de seu métier.

A disposição de escutar o Outro, não é tarefa evidente. Exige um aprendizado a ser conquistado a cada saída de campo, a cada visita para a entrevista, a cada experiência de observação. Os constrangimentos enfrentados pelo desconhecimento vão sendo superados pela definição cada vez mais concreta da linha temática a ser colocada como objetivo da comunicação. Diz-se então que a prática etnográfica permite interpretar o mundo social aproximando-se o pesquisador do Outro "estranho", tornando-o "familiar" ou no procedimento inverso, estranhando o familiar, superando o pesquisador suas representações ingênuas agora substituídas por questões relacionais sobre o universo de pesquisa analisado (Da Matta, 1978 e Velho, 1978). 


\section{$O$ universo de pesquisa, o contexto estudado}

Os Jogadores de futebol de várzea, os fiéis de uma determinada casa de religião, os moradores de uma vila de invasão, os habitantes de um cortiço de esquina de um bairro popular, os grupos de travestis e as prostitutas em seus territórios de batalha, os frequientadores de fast foods, os doadores de rins, os vendedores de artesanato no mercado de pulgas, os voluntários em uma Ong ativista ambiental, os jovens de classe média que "ficam" numa boate, etc, todas estas redes sociais tem sua forma própria de pertencer e viver, construindo realidades culturais próprias.

A escolha do tema de pesquisa leva a opção pela inserção em um contexto social específico que responde a demanda intelectual do(a) antropólogo(a). Questões iniciais de dificuldades ou impedimentos são levadas em conta em torno das condições sociais concretas para a reciprocidade almejada. Sobretudo as pessoas devem estar cientes da intenção do pesquisador e somente na disponibilidade e cumplicidade, a pesquisa tem sua continuidade.

Este lugar não é neutro de sentidos. Cada acontecimento está vinculado ao contexto social em que a ação humana é desenvolvida.

O esforço de construir este cenário social é então fundamental em toda monografia para que os futuros leitores possam compartilhar dos matizes que orientaram os procedimentos sociais nos atos interativos, bem como ter o mínimo de dados sobre as disposições sociais que estavam em jogo nas interações cotidianas. Este contexto é elaborado a partir de dados observados, estudos históricos, revisão bibliográfica de pesquisas já desenvolvidas sobre o tema, análise de discursos e de documentos históricos, estudo de imagens produzidas, etc, enfim, uma gama de dados empíricos e conceituais coletados e interpretados nesta atitude arqueológica de reconstruir o saber produzido sobre o universo social pesquisado.

\section{O exercício da escrita e a ipseidade}

A cada investida "em campo", o(a) etnógrafo(a), segue o modelo clássico fundado pelos primeiros antropólogos que se aventuravam em viagens para conhecer os povos nominados na época de exóticos, simples e distantes. Trata-se do registro escrito em notas, 
diários ou relatos das experiências observadas ou escutadas no cotidiano da investigação.

O que se escreve? Recorremos aqui ao famoso antropólogo brasileiro Darcy Ribeiro (2006) que responde de forma muito simples:

Meus diários são anotações que fiz dia a dia, lá nas aldeias, do que via, do que me acontecia e do que os índios me diziam.

Este ato de escritura define a capacidade de recriar as formas culturais que tais fenômenos adotam e permite exercitar a habilidade de lhes dar vida novamente, agora na forma escrita, com base em uma estrutura narrativa. Eis alguns pontos em comum entre o método etnográfico e o romance, e que aproxima a Antropologia da Literatura.

O antropólogo brasileiro Roberto Cardoso de Oliveira recorre a uma expressão em inglês para definir esta experiência de escrever sobre a experiência de observar o Outro e escutar o Outro: Semantical Gap. Isto quer dizer que o(a) antropólogo(a) vivencia seja na interação face a face, seja no ato de refletir sobre esta experiência, o momento de descoberta do Outro, mas onde o pesquisador faz sempre um retorno a si mesmo porque ele também se redescobre no Outro. $\mathrm{O}$ (a) antropólogo(a) reconhece, ao se relacionar na pesquisa de campo, uma diferença, uma separação de valor, um abismo entre valores que é definido desde a fundação da premissa de estranhar o Outro como de relativismo cultural.

Este momento é uma experiência única e intransferível. Uma busca de conhecimento orientada por conceitos de um campo semântico da teoria antropológica que nos estimula a questões anti-etnocêntricas, quer dizer, de não fazer com que os juízos de valores da sociedade do(a) próprio(a) pesquisador(a) persistam ao olhar o Outro evitando a armadilha de ver o Outro com os valores de uma sociedade tão distante que gere e reproduza o preconceito.

Para muitos uma mescla entre arte e ciência, o método etnográfico se conforma num processo lento, longo e trabalhoso de acesso as inúmeras camadas interpretativas da vida social, e que conforma os fenômenos culturais tanto quanto num laborioso procedimento de reapresentar as formas culturais na qual tal vida social se apresenta para seus protagonistas.

A antropóloga americana Margareth Mead (1979) em um artigo célebre já havia pontuado entre seus colegas que uma das peculiaridades da antropologia, desde suas 
origens, é a de ser uma disciplina de palavras. A autora ao desenvolver seu argumento revela que a prática etnográfica se traduz na memorização de acontecimentos orais complexos (cerimônias, conversas, relatos, comentários, interações verbais, etc.) que necessitam ser registrados, classificados, correlacionados, comparados e, logo após, retomados pelo etnógrafo na forma de estudos monográficos, através do uso de conceitos teóricos e metodológicos do seu campo disciplinar e não do próprio "nativo". Todo(a) o(a) etnógrafo(a) é por assim dizer um(a) escriba.

Para muitos cientistas sociais a sua formação no oficio de etnógrafo passa pelo espinhoso processo da escrita de uma monografia, ou seja, um estudo pontual e denso sobre uma prática cultural qualquer analisada onde necessita transpor para a escrita sua experiência com o grupo pesquisado. $\mathrm{O}$ sofrimento que a escrita traz para este aprendiz de etnógrafo(a) é mais complexa quanto mais ele ou ela se dedicarem ao estudo de práticas cujos contextos culturais são marcados pela forte presença da oralidade na sua forma de expressiva, caso dos estudos de contos e de lendas do folclore popular, de cantos e mitos em sociedades indígenas ou tribais.

A prática da etnografia traz para o campo do debate, hoje, as questões da restituição etnológica, isto é, o retorno ao grupo pesquisado das informações e dados que o(a) etnógrafo(a) deles retirou quando de sua estadia entre eles. Esta foi, sem dúvida, uma das grandes contribuições dos antropólogos americanos que reivindicam uma antropologia pósmoderna. Estes se preocuparam fortemente com estas questões da autoridade etnográfica dos escritos dos antropólogos e do lugar de autor que este ocupa no momento de oferecer a comunidade dos antropólogos suas interpretações da cultura do Outro. Produção de estudos monográficos que apresentam dados, situações, acontecimentos da vida cotidiana do "nativo" cuja natureza é diversa daquela dos dados obtidos no trabalho de campo.

Não cabe no computo deste artigo discutir, mas vale lembrar que a prática da escrita em antropologia (e o trabalho de edição, revisão e editoração) representa um rito de passagem importante para a formação de um antropólogo precisamente pela forma como a linguagem escrita permite ao próprio pensamento antropológico dar conta da natureza do construto intelectual que orienta a representação etnográfica.

Importante se ressaltar que o trabalho de escrita etnográfica tal qual aparece nos estudos monográficos clássicos foi, obviamente, concebido a posteriori, geralmente com o 
apoio de casas de edições interessadas na venda de tais monografias sob a forma de livros. A leitura dos clássicos, tal qual se apresenta no espaço livresco não pode ignorar que a realização de um trabalho etnográfico necessita a prática de um dispositivo de pensamento especulativo preliminar onde a escrita exploratória e ensaística é fundamental para o seu processo de pensar seu próprio pensamento. A organização do trabalho de campo em fases bem precisas, totalmente esquemáticas (preparação, coleta de dados, análise dos dados e escrita final do estudo monográfico, dissertação ou tese) é, neste sentido, uma ilusão criada pelo espaço livresco por onde circulam as etnográficas clássicas do pensamento antropológico e do qual todo(a) o(a) aprendiz de etnógrafo(a) precisa ter acesso.

A escrita etnográfica desde a contribuição de Clifford Geertz ( $O$ antropólogo como autor), de James Clifford (A experiência etnográfica) e de Paul Rabinow (Antropologia da razão) supõe atualmente a pesquisa com novas formas de escritas etno-gráficas como forma de acomodar as questões da controversa da restituição etnológica da palavra do Outro.

\section{Conhecer a trajetória da antropologia como campo de idéias disciplinares}

A prática do método etnográfico é seguida do estudo sistemático da construção do campo da disciplina antropológica. Este procedimento permite a compreensão das disposições intelectuais e ideológicas da trajetória do método antropológico em que o pesquisador se engaja. Compõe-se, portanto, de um dos processos de formação pelos quais um aluno do curso de ciências sociais necessita apreender para se formar na prática de investigação crítica que delimita a produção de conhecimento em Antropologia na sua relação com os demais campos das ditas "sociais".

O encontro/confronto do cientista social com as sociedades não-européias foi evidentemente que deu origem a este modo de conhecimento particular elaborado desde a técnica da observação rigorosa contínua e regular da vida social a partir da localização do investigado no interior das formas da vida social que pretendia estudar. Procurava impregnar-se lenta e sistematicamente dos grupos humanos com os quais mantinha, então, estreita troca e interação. Nas palavras do antropólogo alemão Franz Boas: 
suas alegrias e seus sofrimentos, que tenha conhecido com eles seus momentos de provação e abundância, e que não os encarem como simples objetos de pesquisa examinados como célula num microscópio, mas que os observe como seres humanos sensíveis e inteligentes que são, admitiria que eles nada possuem de um "espírito primitivo, de um "pensamento mágico” ou "prélógico" e que cada individuo no interior de uma sociedade "primitiva" é um homem, uma mulher ou uma criança da mesma espécie possuindo uma mesma forma de pensar, sentir e agir que um homem, uma mulher ou uma criança de nossa própria sociedade. (Boas, 2003, p. 32).

Bronislaw Malinowski e Franz Boas foram os pais fundadores deste método ao explorarem a distância que separava suas sociedades daquelas por eles investigadas. Suas obras, Os argonautas do pacífico ocidental e A alma primitiva, respectivamente, são exemplos da experiência de alteridade na elaboração da experiência etnográfica, tão necessária à formação de um antropólogo, mesmo nos dias de hoje. Diz o antropólogo polonês e posteriormente naturalizado inglês:

Se um homem embarca em uma expedição decidido a provar certas hipóteses e se mostra incapaz de modificar sem cessar seus pontos de vistas e de abandoná-los em razão de testemunhos, inútil de dizer que seu trabalho não terá valor algum. (Malinowski, 1976, p. 65)

Estranhamento e relativização foram conceitos cunhados na tradição do pensamento antropológico na sua tentativa de dar conta dos processos de transformação do olhar o outro, o diferente, desde os deslocamentos necessários do olhar do(a) antropólogo(a) sobre si mesmo e sua cultura, o igual.

A antropologia dos mestres fundadores foi assim responsável, no campo das ciências sociais, por uma revolução epistemológica pela forma como a pesquisa etnográfica, tendo como fundamento o trabalho de campo junto as sociedades ditas primitivas, provocaria nas formas das ciências sociais: produzir conhecimento ao longo do século XX conquistando vigor metodológico na investigação antropológica nas modernas sociedades complexas.

A etnografia como método de investigação das modernas sociedades complexas 
como método de investigação, influenciou as formas de se fazer pesquisa entre os sociólogos da Escola de Chicago. Este grupo de sociólogos americanos e europeus tinha por interesse comum nos anos 30 do século $\mathrm{XX}$, desenvolver um método e conceitos pertinentes para tratar do fenômeno urbano e industrial. Suas descobertas para compreender a sociedade moderna amplificaram seus efeitos nos questionamentos no campo da pesquisa em ciências sociais pela forma como a etnometodologia encontrou nos estudos clássicos dos antropólogos sua fonte de inspiração para o estudo microscópico das formas de vida social de nossas próprias sociedades na cultura ocidental, urbano-industrial.

No inicio do séc. XX, principalmente após as crises dos anos 1930, eram inúmeros os cientistas sociais que participavam de instituições públicas ou privadas que tinham por centro de suas ações o trabalho com grupos e/ou indivíduos vivendo em situações de crise social. Muitos destes cientistas fizeram destas experiências seu tema e objeto de teses em universidades efetuando-se assim a passagem da participação para a observação das situações vividas por tais indivíduos e/ou grupos, numa tentativa de reuni-los no interior de um mesmo procedimento metodológico.

A etnometodologia foi neste caso fundamental para a pesquisa no campo das ciências sociais migrarem de procedimentos e técnicas de pesquisa influenciadas por uma sociologia funcionalista ou positivista para uma microsociologia com grande influência do método etnográfico, em Antropologia. Um exemplo paradigmático é a Escola de Chicago que influenciou grandemente os estudos antropológicos em sociedades complexas, em especial orientando para a análise das práticas culturais no contexto da vida social nos grandes centros urbanos. Reunindo esta experiência ao método etnográfico, a área de conhecimento da Antropologia inovou em suas formas de pesquisar os fenômenos sociais nas modernas sociedades urbano-industriais ao propor o conceito de relativização como inerente à pesquisa em ciências sociais, resultado do jogo polêmico entre participação e distanciamento do pesquisador em relação ao seu próprio território de pesquisa.

Outra forma de se produzir conhecimento em ciências sociais se expande desde aí tendo como foco o tema das necessárias rupturas epistemológicas, conforme Pierre Bourdieu (1999). Para o sociólogo francês tal pesquisa necessita contemplar o sentido reflexivo da trajetória dos conceitos e teorias produzidos superando a força e a qualidade heurística das ditas ciências duras. A apresentação do mundo subjetivo do pesquisador 
como parte integrante dos procedimentos científicos de objetivação a pesquisa do mundo social e não como impedimentos a sua realização encontram na história das técnicas de pesquisa em antropologia uma fonte de inspiração.

\section{Aprender a etnografia lendo etnografias}

A pergunta do(a) aluno(a) ao professor(a) antropólogo(a) é freqüente: "como posso aprender a fazer uma boa etnografia? Existe algum modelo que possas me sugerir? Tenho pressa".

$\mathrm{O}$ (a) professor(a) antropólogo(a) sempre responde da mesma forma. Não existe nenhuma "receita de bolo" pronta ou "cursinho Walita" 2 a seguir. Você pode começar por ler o Manual etnográfico de Marcel Mauss ou os vários livros que buscam sistematizar as técnicas de pesquisa etnográfica. Mas somente lendo boas etnografias, os diários, as crônicas de viajantes, uma boa literatura, os laudos de pesquisa, os relatos de campo, somado ao estudo sistemático de abordagens teóricas, é que você conseguirá passar pelo processo de formação epistemológica na experiência etnográfica.

$\mathrm{O}$ (a) aluno(a) conformado(a) de que a pressa não adiantará de nada, entenderá que a prática da etnografia se baseia nesta disponibilidade de pesquisar a partir de um método que o(a) coloque no encontro direto com os indivíduos e/ou grupos em situações de vida ordinárias.

Lendo os chamados clássicos da etnografia, o(a) aprendiz configura o que significa a experiência do(a) etnógrafo(a) misturar-se no seio do grupo social, colocando-se em perspectiva a partir de conversas, diálogos que nascem das interações sempre na expectativa de compreender as intenções e motivações que orientam as ações dos Outros e as suas. Desvenda aos poucos os acontecimentos (rituais, cerimônias, eventos, conflitos, solidariedades, etc.) particulares, interpretando os sentidos nele contidos. Pela leitura das etnografias, o(a) pesquisador(a) vai participando cada vez mais de uma comunidade de comunicação que compartilha de um estilo de produção do conhecimento, sempre orientado(a) por interrogações e inquietações de seu tema e objeto de pesquisa: o que está se passando naquele momento em que um determinado acontecimento esta ocorrendo?

${ }^{2}$ Cursinho Walita resultou de uma publicidade da venda de liquidificadores Walita que sugeriam receitas de culinária rapidamente elaboradas com o uso do aparelho. 
Quem faz o quê nestas situações? Quem é quem na ordem destes acontecimentos? Quais as razões de tudo aquilo se passar da forma como está se passando? Quais as razões das coisas serem como são?

Baseado no aprendizado da leitura etnográfica, o(a) pesquisador(a) perde este lugar de "mal necessário" e se torna provocador de questões mais pontuais sobre a vida das pessoas e dos grupos com as quais está dialogando, convidando-os a pensar sobre o sentido de suas práticas cotidianas. No interior deste diálogo o(a) etnógrafo(a) transforma, assim, os acontecimentos ordinários da vida dos indivíduos e/ou dos grupo com os quais interage em evento extra-ordinário, promovendo entre eles o desafio de refletir conjuntamente sobre si mesmos.

\section{As implicações de ser um etnógrafo: a vigilância epistemológica}

O método etnográfico se define pelas técnicas de entrevista e de observação participante complementares aos procedimentos importantes para o cientista adequar suas preocupações estritamente acadêmicas e academicistas à trama interior da vida social que investiga. Uma das razões pela qual na etnografia a entrevista transcorre desde a elaboração da estrutura de um roteiro de inquietações do(a) pesquisador(a) flexível o suficiente para aderir as situações subjetivas que estão presentes no encontro etnográfico.

A preocupação desmedida do(a) pesquisador(a) com a estrutura de uma entrevista dirigida, quase transformado em questionário, e sua insistência no afastamento do entrevistado de uma reflexividade sobre suas situações de vida ordinária, em antropologia, pode conduzir o etnógrafo muitas vezes ao desencontro etnográfico e, até mesmo, ao desconforto do desinteresse por parte do grupo de investigação. Ao contrário, as relações de reciprocidade, mesmo que oscilantes em dias de pesquisa ditos mais produtivos e outros permeados de dificuldades de toda ordem (o informante que "deu bolo", a desconfiança de um entrevistado sobre a fidelidade de suas concepções, etc), são construídas em situações de entrevistas livres, abertas, semi-guiadas, repletas de trocas mútuas de conhecimento.

Além destas duas técnicas associadas ao método etnográfico, existe outra, de extrema importância para todo o(a) antropólogo(a), a técnica da escrita do diário de campo. Após cada mergulho no trabalho de campo, retornando ao seu cotidiano de antropólogo, o 
etnógrafo necessita proceder a escrita de seus diários de campo. Os diários íntimos dos antropólogos trazem farta bibliografia sobre os medos, os receios, os preconceitos, as dúvidas e as perturbações que o moveram no interior de uma cultura como forma de compreensão da sociedade por ele investigada. Trata-se de anotações diárias do que o(a) antropólogo(a) vê e ouve entre as pessoas com que ele compartilha um certo tempo de suas vidas cotidianas. Os diários de campo, entretanto não servem apenas como um instrumento de "passar a limpo" todas as situações, fatos e acontecimentos vividos durante o tempo transcorrido de um dia compartilhado no interior de uma família moradora de uma vila popular, com quem passou um tempo para pesquisar o tema da violência urbana. Ele é o espaço fundamental para o(a) antropólogo(a) arranjar o encadeamento de suas ações futuras em campo, desde uma avaliação das incorreções e imperfeições ocorridas no seu dia de trabalho de campo, dúvidas conceituais e de procedimento ético. Um espaço para o(a) etnógrafo(a) avaliar sua própria conduta em campo, seus deslizes e acertos junto as pessoas e/ou grupos pesquisados, numa constante vigilância epistemológica.

Evidentemente que o diário de campo não é algo que possa ser escrito ao mesmo tempo em que me encontro compartilhando com os outros suas vidas, no dia a dia! Ele resulta de outro instrumento: o caderno de notas. É no caderno de notas de campo, onde o(a) antropólogo(a) costuma registrar dados, gráficos, anotações que resultam do convívio participante e da observação atenta do universo social onde está inserido e que pretende investigar; é o espaço onde situa o aspecto pessoal e intransferível de sua experiência direta em campo, os problemas de relações com o grupo pesquisado, as dificuldades de acesso a determinados temas e assuntos nas entrevistas e conversas realizadas, ou ainda, as indicações de formas de superação dos limites e dos conflitos por ele vividos.

O caderno de notas e o diário de campo são instrumento de transposição de relatos orais e falas obtido desde a inserção direta do(a) pesquisador(a) no interior da vida social por ele ou por ela observada. Muitos destes cadernos de notas e diários contendo dados brutos de observações diretas em campo conduziram os antropólogos ao estudo e a pesquisa, por exemplo, com as gramáticas e os vocabulários que constituem os diferentes dialetos de uma mesma língua falados pelas sociedades por eles pesquisadas, com as genealogias de parentesco que organizam seu corpo social; os mitos e os rituais que vivificam o sentido coletivo de suas vidas, etc. 
Nos termos de Roberto Cardoso de Oliveira (2000), ver, ouvir e escrever como parte integrante da prática da etnografia não se limita a ações simples, mas giram em torno das implicações do pesquisador com sua pesquisa uma vez que ela repousa sobre a qualidade e densidade das trocas sociais do(a) antropólogo(a) com os grupos com os quais esta compartilhando experiências. O resultado de um trabalho de campo se mede pela forma como o(a) próprio(a) antropólogo(a) vai refletir sobre si mesmo na experiência de campo. A confrontação pessoal com o desconhecido, o contraditório, o obscuro e o confuso no interior de si-mesmo é uma das razões que conduzem inúmeros autores a considerar a etnografia como uma das práticas de pesquisa mais intensas nas ciências sociais. Não raro, os diários são hoje publicados ou revistos para publicação pelos(as) próprios(as) antropólogos(as) como é o caso do "Os diários e suas margens, viagem aos territórios Terêna e Tükúna" de Roberto Cardoso de Oliveira em uma clara intenção de devolução da obra escrita e fotografada aos povos indígenas hoje em crescente índice de alfabetização e tomados agora como leitores potenciais de sua própria história registrada e relatada pelo antropólogo (Cardoso de Oliveira, 2002, p. 13).

Esta crescente circularidade das produções etnográficas elaboradas no âmbito acadêmico para contextos além-muros universitários consiste numa perspectiva de democratização e compartilhamento político do trabalho de pensar o mundo social. Como esclarece o antropólogo americano Marshall Sahlins:

Agora, duzentos anos mais tarde, uma marcada consciência de "cultura" está reaparecendo no mundo todo entre as vítimas atuais e passadas da dominação ocidental - é como expressão de exigências políticas e existenciais semelhantes. Esse culturalismo, tal como foi chamado, está entre os mais surpreendentes, e talvez mais significativos fenômenos da história do mundo moderno. (Sahlins, 2001, p. 28)

\section{A tendência monográfica e a grafia da luz}

A pesquisa elaborada no suporte escrito segue a tendência monográfica tendo por projeto acadêmico divulgar e circular a descrição da experiência etnográfica.

A prática da escrita tem sido o espaço da produção intelectual do etnógrafo por 
excelência. A escrita de artigos, de ensaios, de livros, de teses e dissertações ou de trabalhos monográficos tem sido a forma adotada para a expressão final de um trabalho de campo com base no método etnográfico, a ser reconhecido pelos pares do mundo acadêmico.

Entretanto, assiste-se ao longo do último século, uma re-orientação desta tendência no sentido de agregar a ela a produção de etnografias através do uso de recursos audiovisuais como foi o caso da adoção da câmera fotográfica por Bronislaw Malinowski, entre os trombriandeses e por Margaret Mead e Gregoire Bateson entre os balineses, para citarmos apenas alguns entre outros antropólogos(as) que produziram imagens nas experiências de campo nos primeiros cinqüenta anos do século XX.

O antropólogo visual australiano David MacDougall (2006), reflete sobre estas questões que decorrem do uso do método etnográfico na pesquisa em ciências sociais. Ele afirma que a produção textual de etnografias tem seus limites expressos no fato de que a linguagem escrita re-apresenta as diferenças culturais sob uma forma esquemática em detrimento da concretude da experiência etnográfica traduzida, por exemplo, pela via da fotografia e do filme. Na produção textual, segundo o autor, o "nativo" se deixa ver pela mão do etnógrafo, desde um ponto de visa generalizante, abstrato e normativo da palavra escrita em seu desespero de expressar as formas como os fenômenos foram vividos em campo pelo(a) antropólogo(a). Outro fator determinante da escrita etnográfica é que na medida em que o texto circula e é reinterpretado pelo ato da leitura, os dados etnográficos se depositam na forma de uma produção textual e se tornam pouco a pouco independentes de seu contexto original de enunciação, pois são reinterpretados desde outros lugares e contextos de leituras.

Estas questões sobre as modalidades de escrita do pensamento antropológico tecer suas interpretações sobre a cultura "nativa" são aspectos fundamentais do avanço nos usos dos procedimentos e técnicas dos recursos audiovisuais para a prática da pesquisa de campo em Antropologia nos últimos 30 anos. Se antes a expressão figurativa do outro poderia ser vista negativamente porque congelava a cultura do nativo e o próprio nativo numa imagem determinada, alusiva apenas a um momento de sua vida compartilhada com o etnógrafo que o fotografou e o filmou, durante seu trabalho de campo, hoje, este mesmo traço figurativo já se coloca de outra forma: através do olhar de uma tradição interpretativa em antropologia 
que, longe da ingenuidade positivista, não atribui a imagem técnica seu estatuto de duplo ou cópia do real.

Acumulados ao longo dos anos nos acervos pessoais dos antropólogos ou nos arquivos institucionais as imagens visuais e sonoras captadas e registradas do nativo e de sua cultura durante os vários momentos do trabalho de campo permitem precisamente avaliar o grau de impacto da presença do etnógrafo entre a população por ele estudada.

Para David MacDougalll (2006) o caráter figurativo da imagem fotográfica e filmica (hoje, cada vez mais videográfica) ao mesmo tempo em que permite a quem as manipula pensar nas semelhanças e diferenças entre ele e a cultura retratada na imagem, conduz a uma reflexão sobre a passagem do tempo do qual estas imagens resultam. Precisamente por que é o seu traço figurativo que podemos perceber quase como pistas, desvendando os gestos e motivações simbólicas que orientaram o olhar etnográfico para a composição daquela forma de representação do nativo e não de outra.

\section{Etnografia e as novas tecnologias}

Até recentemente, o leitor era orientado a ler na interface de um livro ou a olhar as imagens ilustrativas anexas para conhecer e compartilhar da experiência etnográfica e do potencial analítico conceitual do(a) antropólogo(a) em sua objetividade científica. Após os aprendizados com a interface da fotografia e do cinema, é na era das textualidades eletrônicas que se renova o desafio da metamorfose da escrita etnográfica. Neste contexto, o clique aqui é o convite de um contrato de trocas complexas e efêmeras, que colocam autrement o ato sempre possível da interatividade entre o pesquisador e os sujeitos da interpretação.

Vale ressaltar que uma das últimas fronteiras, hoje, é a produção de novas escritas etnográficas com base no contexto enunciativo que constituem as novas textualidades eletrônicas e digitais. Uma antropologia do cyberspace ou no cyberspace é hoje uma das formas possíveis de expressão do trabalho de campo em Antropologia através do uso do método etnográfico clássico em ambientes virtuais, o que tem gerado uma reflexão cada vez maior em torno do processo de desterritoralização da representação etnográfica e a desmaterialização do texto etnográfico no âmbito das ciências sociais. 
O processo de desencaixe espaço-tempo que as novas tecnologias da informática têm proposto para os lugares da memória no corpo da sociedade contemporânea, ao configurar as relações entre homem e cosmos em redes mundiais de comunicação, tem provocado, nas ciências humanas, a necessidade de se aprofundarem novas formas de entendimento das estruturas espaço-temporais que conformam a magia dos mundos virtuais.

Para enfrentar esse e outros desafios, o que se coloca, cada vez mais, é a relevância não apenas de refletir sobre as diferentes modalidades de tecnologias de pensamento (oralidade, escrita, redes digitais) empregadas pelas sociedades humanas para liberar a memória de seu suporte material (seguimos aqui Leroi-Gourhan, 1964) até atingir sua expressão recente em redes eletrônicas e digitais, mas, principalmente, de indagar a respeito das operações e proposições por meio das quais as ciências humanas têm enfrentado, até o momento, o conhecimento da matéria do tempo e suas cadeias operatórias.

Importa, aqui, tratar da cultura da tela (Eckert e Rocha, 2005) e da civilização da imagem (Durand, 1980) como novas formas de reorganização dos saberes que suportes mais tradicionais disponibilizam, transfigurando seu sentido original e atribuindo-lhes uma significação mais móvel, plural e instável pelo caráter granular que atribui a todos eles.

Pode-se supor a possibilidade de uma etnografia hipertextual (Eckert e Rocha, 2005), com base numa retórica mais aberta, dinâmica, fluida de disponibilização dos dados etnográficos em web tanto para o pesquisador quanto para sua comunidade lingüística, o que contempla uma alteração na forma como até então as ciências sociais vinham produzindo conhecimento.

\section{Conclusões}

Os fundamentos da prática etnográfica, portanto, apontam, assim, para o papel que assume o pesquisador da área das ciências sociais na sua investigação da vida social no coração dela, uma questão que se tornou central, principalmente nos anos 50 e 60 do século $\mathrm{XX}$, mais particularmente quando o objeto da Antropologia migra das sociedades ditas

primitivas para as sociedades dos próprios antropólogos. O papel do etnógrafo diante da coisa e das pessoas por ele pesquisadas, seu grau de implicações com elas, sua forma de participar no transcurso dos processos da vida social que se modifica e transforma no tempo 
e no espaço, configura-se na própria delimitação do trabalho de campo segundo a situação que nela ocupa o pesquisador em relação ao fenômeno etnografado.

Em antropologia, a dissimulação do(a) etnógrafo(a) (sua profissão, seus objetivos, suas intenções, etc.) no interior do grupo a ser pesquisado desencadeia inconvenientes de ordem ético-moral que tem sido debatido pela sua comunidade de pesquisadores que tendem a rejeitar a situação em que o(a) antropólogo(a) esconde suas verdadeiras intenções em campo. A figura do(a) antropólogo(a) travestido de nativo é, portanto, rara na prática do método etnográfico colocando em risco precisamente o pacto de confiança e cumplicidade com o grupo que investiga e desde aí comprometendo a natureza dos dados por ele obtidos.

O método etnográfico opera precisamente com esta distensão infinita do(a) antropólogo(a) diante de si e do outro, sendo no interior deste vazio de sentido que brota sua reflexão sobre as culturas e sociedades humanas.

Importante se frisar que duração de uma etnografia não é a mesma da duração da temporalidade do próprio fenômeno social e cultural investigado. Desde suas origens, a prática do trabalho de campo em Antropologia vem confrontando situações de extrema complexidade, nem sequer imaginadas pelos seus pais fundadores. Cada vez mais investigando os fenômenos de sua própria sociedade, o(a) antropólogo(a) ao usar o método etnográfico se confronta com difíceis questões ético-morais no delineamento de suas relações com as pessoas e/ou grupos sociais por ele pesquisados.

Neste sentido, a prática da etnografia no mundo pós-colonial desdobraram-se em importantes debates sobre o lugar do(a) antropólogo(a) e das ciências sociais no âmbito, por exemplo, das lutas pelos direitos humanos e dos direitos sexuais no mundo contemporâneo. Esta complexidade decorre da interdependência que une hoje o oficio do(a) antropólogo(a) as formas de vida dos interlocutores, onde muitas vezes se vê constrangido a participar das atividades de lutas de defesa das suas culturas.

Se antes o ato de participar que configurava a técnica da observação participante não trazia consigo o engajamento do(a) antropólogo(a) nas mudanças das formas de ser da cultura nativa, hoje, o método etnográfico não pode ignorar que o próprio trabalho de campo do(a) antropólogo(a) provoca nela intervenções, a ponto de ser um fator de transformação da cultura do "nativo".

Acusada inúmeras vezes de produzir um conhecimento insípido e inodoro das 
sociedades humanas, pela forma inicial com que advogava a necessidade do(a) antropólogo(a) conservar em campo uma certa distância do fenômeno observado, tendo em vista suas preocupações com o rigor científico, a tradição etnográfica se transformou lentamente em expressão de uma forma de produção de conhecimento engajada e, por vezes, até mesmo militante. Com o passar das décadas, em fins do séc. XX, situados na defensiva diante de um modelo positivista ou da radicalidade de um modelo militante nas formas de procederem às apropriações do método etnográfico, alguns antropólogos inspirados numa tradição interpretativista re-orientam para as tensões entre participação e distanciamento como inerentes à condição do tradicional ato de "etnografar" as culturas nas mais diversas sociedades.

Mais ou menos participante, o debate em torno das tipologias da técnica da observação participante que orienta o método etnográfico e seus graus variados de implicações do(a) antropólogo(a) com o grupo pesquisado (até se chegar a controversa da pesquisa-ação ou pesquisa participante) fez avançar a própria importância deste método para a formação de um cientista social no campo da produção de conhecimento antropológico. O que coloca a etnografia como uma forma fundamental de construção de conhecimento nas ciências sociais é justamente esta sua abertura ao mundo das interações sociais e culturais que unem o pesquisador às culturas e sociedades por ele investigadas e que reside em algumas perguntas cruciais sem que por isto se tenha para elas uma resposta única: Como conciliar a necessidade metodológica do pesquisador se implica na vida cotidiana de um grupo humano e a implicação do(a) pesquisador(a) que desde aí decorre com a forma da vida humana que ele configura? Como evitar nos tornarmos nós mesmos « nativos » ou de transformar os "nativos" em nós?

A ruptura com o senso comum sem dúvida é hoje uma questão que provoca verdadeira vertigem entre os cientistas sociais se pensarmos que neste "senso comum" estão as suas próprias produções teóricas e conceituais. Na figuração de um tempo póscolonial, o Outro, o Diferente, é ameaçado de se tornar o Mesmo, o igual, e isto pelas mãos dos próprios etnógrafos ou dos "nativos" transformados em antropólogos imbuídos da invenção ocidental da figura do "nativo" universal.

Segundo Sahlins (2001) no desencaixe espaço-tempo do mundo pós-colonial, no encurtamento das distâncias que colocam o pesquisador e sua produção no interior do "olho 
do furacão" das guerras e disputas entre povos e culturas em busca de seus destinos, o apelo moral da noção de nativo universal e da privação que ela impõe as possibilidades de compreensão da experiência nativa, fora de suas particularidades ou pressupostos culturais, como sugere a teoria perspectivista, se tornou hoje outro dos grandes desafios da permanência do método etnográfico no campo das pesquisas sociais.

A prática etnográfica tem por desafio compreender e interpretar tais transformações da realidade desde seu interior. Mas, sabemos também, que toda produção de conhecimento circunscreve o trajeto humano. Assim o oficio de etnógrafo pela observação participante, pela entrevista não-diretiva, pelo diário de campo, pela técnica da descrição etnográfica, entre outros, coloca o(a) cientista social, o(a) antropólogo(a), mediante o compromisso de ampliar as possibilidades de re-conhecimento das diversas formas de participação e construção da vida social.

\section{Referências Bibliográficas}

BACHELARD, G. A formação do espírito científico. Rio de Janeiro, Contraponto, 1996.

BERGER, Peter L. e LUCKMANN, Thomas. A construção social da realidade. Petrópolis, Vozes, 1973.

BOAS, Franz. L'art primitif. Paris, Adam Biro, 2003.

BOURDIEU, Pierre et alli A profissão de sociólogo, preliminares epistemológicas. Petrópolis, Editora Vozes, 2002.

CALDEIRA, Teresa Pires do Rio. "A presença do autor e a pós-modernidade em Antropologia". In: NOVOS ESTUDOS CEBRAP. n 21, julho 1988.

CALDEIRA, Teresa. "Uma incursão pelo lado 'não respeitável' da pesquisa de campo". Ciências Sociais Hoje, 1. Trabalho e cultura no Brasil. Recife, Brasília, CNPq ANPOCS, 1981.

CARDOSO DE OLIVEIRA, Roberto. O trabalho do antropólogo. SP, Unesp, 2000.

CARDOSO DE OLIVEIRA, Roberto. Os diários e suas margens. Brasília, UNB, 2002.

CASTRO, Eduardo B. Viveiros de. "O campo na selva, visto da praia". XIV Encontro Anual da ANPOCS, 22 a 26 de outubro de 1990. Caxambu, Minas Gerais.

CLIFFORD, James. A experiência etnográfica: antropologia e literatura no século XX. RJ, Ed UFRJ, 1998.

COULON, Alain. L'ethnométhodologie. Paris, PUF, 1987.

COULON, Alain. A escola de Chicago. Campinas, Papirus Editora, 1995.

DA MATTA, Roberto. "O oficio de etnólogo, ou como ter anthropological blues". In: NUNES, Edson de Oliveira (organizador). A aventura sociológica: objetividade, paixão, improviso e método na pesquisa social. Rio de Janeiro, Zahar, 1978. p. 23-35

DA MATTA, Roberto. Relativizando, uma introdução a antropologia social. Rio de Janeiro, Petrópolis, 1981.

DURAND, Gilbert. Les structures anthropologiques de l'imaginaire. Paris, Dunod, 1980.

ECKERT, Cornelia e ROCHA, Ana Luiza Carvalho da. "Imagens do tempo nos meandros da memória: por uma etnografia da duração". In: Koury, Mauro G P. (org.). Imagem e Memória: Estudos em Antropologia Visual. Rio de Janeiro: Garamond, 2000.

ECKERT, Cornelia e ROCHA, Ana Luiza Carvalho da. "Escrituras hipermídiaticas e as 
metamorfoses da escrita etnográfica na era das textualidades eletrônicas." In: SEL, Susana. Imágenes y Medios en la Investigación Social. Una mirada latinoamericana. Buenos Aires, UBA e FFL, 2005. p. 65 a 78.

ECKERT, Cornelia e ROCHA, Ana Luiza Carvalho da. O tempo e a cidade. Porto Alegre, Editora da UFRGS, 2006.

ECKERT, Cornelia e ROCHA, Ana Luiza. Etnografia de rua e câmera na mão. Revista Eletrônica Studium. http://www.studium.iar.unicamp.br/oito/2.htm?=

FOOTE WHYTE, William. Sociedade de Esquina. RJ, Jorge Zahar Editor, 2005.

GEERTZ, Clifford. A interpretação das culturas. Rio de Janeiro, Zahar Editores, 1978.

GEERTZ, Clifford. Obras e vidas: o antropólogo como autor. Rio de Janeiro: Editora. UFRJ, 2002.

LEIRIS, Michel. L'Afrique Fantôme. Paris, Gallimard, 1934.

LEROI-GOURHAN, Andre. Le geste et la Parole, Paris, Albin-Michel, 1964.

LÉVI-STRAUSS, Claude. "Introdução à Obra de Marcel Mauss". In: Sociologia e Antropologia. SP, EPU/EDUSP, 1974, p.1-36.

LEVY-BRUHL, Lucien. Carnets. Paris, PUF, 1998.

MACDOUGALL, David. The visual in Anthropology. In. The corporeal image. Film, ethnography and the senses. Princeton, New Jersey, Princeton University Press, 2006.

MALINOWSKI, Bronislaw. Argonautas do Pacífico Ocidental. São Paulo, Abril Cultural, Pensadores, Atica, 1976.

MEAD, Margareth. "Anthropologie visuelle dans une discipline verbale". In: Pour une anthropologie visuelle, France, C. (org). Paris, Mouton, 1979.

PEIRANO, Mariza. Uma antropologia no plural. Três experiências contemporâneas. Brasília, Ed. UNB, 1991.

RABINOW, Paul. Antropologia da Razão. Rio de Janeiro, Relume Dumará, 1999.

RIBEIRO, Darcy. Diários Índios. São Paulo, Cia das Letras, 2006.

RICOEUR, Paul Tempo e Narrativa. São Paulo, Editora Papirus, 1994.

SAHLINS, Marshall. Como pensam os nativos. São Paulo, EDUSP, 2001.

THIOLLENT, Michel. Critica metodológica. Investigação social e enquête operária. São Paulo, Polis, 1980.

VELHO, Gilberto. "Observando o familiar". In: NUNES, Edson de Oliveira (organizador). A aventura sociológica: objetividade, paixão, improviso e método na pesquisa social. Rio de Janeiro, Zahar, 1978. p. $36-46$

VELHO Gilberto. (org.). O desafio da cidade. Rio de Janeiro. Ed. Campus, 1979.

WINKIN, Yves. A nova comunicação. São Paulo, Papirus, 1998. 